\title{
GIARDIA-INFECTION AMONG SUBJECTS REVEALED DIARRHEA OR PASSAGE OF SOFT STOOL IN KOCHI PREFECTURE, JAPAN
}

\author{
Norihito Morimoto ${ }^{1 *}$, Masataka Korenaga ${ }^{2}$, Chizu Komatsu ${ }^{1}$, \\ Masanori Morita ${ }^{3}$, Sigeyoshi Sugihara ${ }^{1}$, Koichi Saika ${ }^{1}$, \\ MASAAKI NISHIDA $^{1}$, MASAHIde SASAKI ${ }^{1,4}$ AND Yoshinisa HaShigUCHI ${ }^{2}$ \\ Received March 20, 1998/Accepted June 1, 1998
}

\begin{abstract}
Prevalence of Giardia spp. infection was determined among subjects attending Kochi Medical School Hospital from April 1996 to January 1998. Cysts of Giardia spp. were found in $10(0.6 \%)$ out of 1,702 stool samples examined. Infection rate was higher among aged males. Most of the subjects with Giardia organisms had no history of traveling overseas except 2 cases. Although source of infection was not determined, most of the positive subjects supposed to be infected within the community.
\end{abstract}

Key word: Giardia, Giardiasis, Diarrhea, Soft feces, Advanced age group

\section{INTRODUCTION}

Giardiasis is one of the common intestinal protozoan infections. This disease is prevailing in developing countries (Tompson et al., 1993). Even in developed countries, infections with Giardia spp. have been reported from day-care centers (Pickering et al., 1981). Food-borne transmission (Peterson et al., 1988) and water-borne transmission (Moorehead et al., 1990) have also been reported. Reflecting recent advancement in international interchange and traveling abroad, imported cases have been increasing in Japan. In addition, a close association between sexually-transmitted diseases and protozoan infection has been focused (Takeuchi and Miyahira, 1989). To date, several data on prevalence of giardiasis diagnosed by stool examination have been reported by health screening and from admitted patients in different 2 hospitals in metropolitan area and Tokai region in Japan (Kado et al., 1986; Ichizawa et al., 1990). However, a few cases regarding the disease have been reported from Shikoku region, especially from Kochi Prefecture, which is different from other metropolitan area in socio-economics as well as population structure including life styles of the people.

\section{SubJects AND Methods}

\section{Study subjects}

Stool samples were collected from 1,702 subjects of 0-94 years of age who visited the Kochi Medical School Hospital either as admitted or outpatients from April 1996 to January 1998. These subjects included 950 males and 752 females who had either history of diarrhea or passage of soft stool.

\section{Stool examination}

Fecal specimens were examined microscopically by the direct smear method for trophozoites or cysts of Giardia spp. To confirm Giardia-positive cases, they were processed by Wright's solution or modified Kohn' s one-step staining (Gleason and Healy, 1965). Smears from diarrhea samples were also stained with modified Ziehl-Neelsen carbol-fuchsin to detect Cryptosporidium oocysts (Henriksen and Pohlenz, 1981).

\section{Examination of blood}

Blood was tested for peripheral blood cell counts, immunoglobulin assay and biochemical analysis before and after the treatment in patients with Giardia parasites. Particle agglutination tests (Fujirebio, Tokyo, Japan) were performed for the measurement of serum antibody against human $\mathrm{T}$-cell lymphotropic virus-type

1 Depertment of Clinical Laboratory, Kochi Medical School, Nankoku, Kochi 783-8505, Japan ( ${ }^{*}$ corresponding author)

2 Depertment of Parasitology, Kochi Medical School

3 Depertment of Internal Medicine, Kochi Medical School

4 Depertment of Clinical Laboratory Medicine, Kochi Medical School 
Table 1 Age and sex-distribution of subjects examined for Giardia infection

\begin{tabular}{cccccc}
\hline & & \multicolumn{2}{c}{ Male } & \multicolumn{2}{c}{ Female } \\
\cline { 3 - 6 } Age (years) & Total examined & Negative & Positive (\%) & Negative & Positive (\%) \\
\hline 10 & 87 & 55 & $0(0.0)$ & 32 & $0(0.0)$ \\
$11-20$ & 70 & 31 & $0(0.0)$ & 39 & $0(0.0)$ \\
$21-30$ & 73 & 34 & $0(0.0)$ & 39 & $0(0.0)$ \\
$31-40$ & 79 & 37 & $0(0.0)$ & 42 & $0(0.0)$ \\
$41-50$ & 188 & 90 & $0(0.0)$ & 98 & $0(0.0)$ \\
$51-60$ & 257 & 133 & $2(1.5)$ & 121 & $1(0.8)$ \\
$61-70$ & 507 & 308 & $5(1.6)$ & 194 & $0(0.0)$ \\
$71-80$ & 361 & 214 & $1(0.5)$ & 146 & $0(0.0)$ \\
$\geqq 81$ & 80 & 39 & $1(2.6)$ & 40 & $0(0.0)$ \\
\hline Total & 1,702 & 941 & $9(1.0)$ & 751 & $1(0.1)$ \\
\hline
\end{tabular}

I (HTLV-I).

\section{Statistical analysis}

Contingency table analysis was used to determine the probability of significant differences between the sex and age groups. Paired $t$ test was applied to evaluate hematological data. A value $(P)$ of less than 0.05 was considered significant.

\section{RESULTS AND DISCUSSION}

The prevalence rate of positive cases for Giardia organisms is shown by sex and age in Table 1. Out of 1,702 subjects examined in the present study, stool samples from 10 subjects $(0.6 \%)$ consisting of 9 males and 1 female were positive for cysts of Giardia by microscopic examination. In most of the cases, only cysts of Giardia spp. were found in fecal samples. Trophozoits were observed in fecal samples from 2 cases and bile sample from one patient. The species of the genus Giardia have

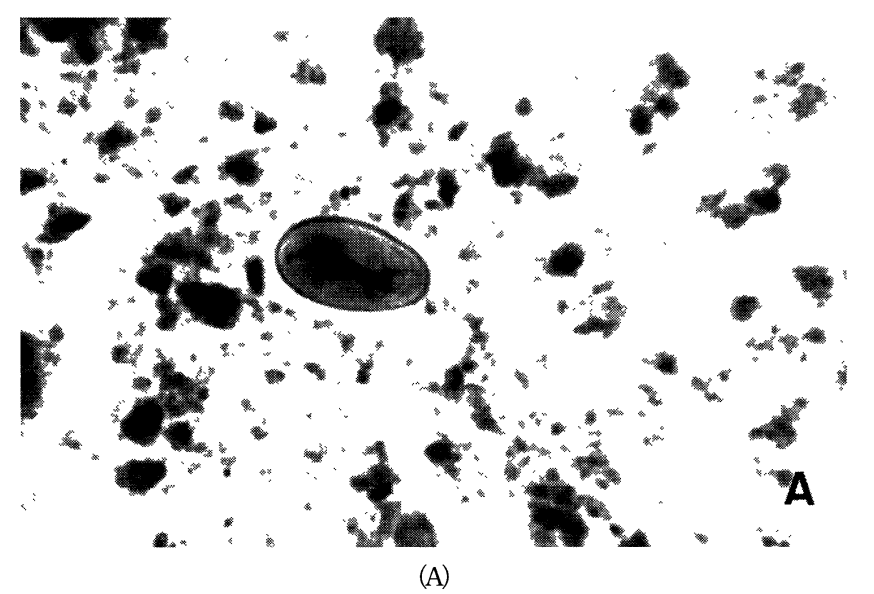

been reported to be divided into three groups (G. agilis group, G. muris group and G. duodenalis ( $=G$. intes tinalis $=G$. lamblia $)$ group) differing in the shape and position of the median bodies, the shape of the cell, and the relative length of the adhesive disk (Kulda and Nohýnková, 1978; Tompson et al., 1993). The morphology of the trophozoites observed was pyriform in shape (body length; $13.6 \pm 1.3 \mu \mathrm{m}$, adhesive disk length; $6.3 \pm 0$. $6 \mu \mathrm{m}, \mathrm{n}=30$ ) and the median body was situated approximately across the body (Fig 1). Based on these morphological features, the organisms were identified as trophozoites of Giardia lamblia. To date, it is not possible to distinguish morphologically the cyst of $G$. lamblia from that of other Giardia spp. Therefore, it should be necessary to develop a molecuar genetic analysis, using PCR, in the future to identify the species of the cysts in the fecal samples. In this study, Cryptosporidium and other protozoa were not found in diarrheal stool samples examined. The characteristic

Figure 1 (A) Cyst of Giardia stained with modified Kohn's one-step staining $(\times 1,000)$. (B) Trophozoite of $G$. lamblia Stained with Wright's solution. The median body (MD) is situated approximately across the body $(\times 1,000)$. 
Table'2 Summary of the subjects with Giardia organisms

\begin{tabular}{|c|c|c|c|c|c|c|c|}
\hline No. & $\begin{array}{c}\text { Age } \\
\text { (years) }\end{array}$ & Sex & $\begin{array}{l}\text { Travel } \\
\text { History* }\end{array}$ & $\begin{array}{l}\text { Detection of } \\
\text { trophozoites }\end{array}$ & Symptoms $^{\dagger}$ & $\begin{array}{l}\text { Clinical } \\
\text { History }\end{array}$ & Drug $\S$ \\
\hline 1 . & 69 & M & SEA & - & Abdominal pain, ailment & Cancer (tongue) & $\mathrm{N}$ \\
\hline 2 . & 72 & M & NA & - & NA & Cardiac disease, Diabetes mellitus & NA \\
\hline 3 . & 61 & M & $\mathrm{N}$ & - & Diarrhea, Abdominal ailment & Cancer (lung) & $\mathrm{CD}$ \\
\hline 4 . & 68 & M & $\mathrm{N}$ & + & $\mathrm{N}$ & Cancer (lung) & $\mathrm{N}$ \\
\hline 5 . & 60 & M & $\mathrm{N}$ & + & Diarrhea, Abdominal ailment & Cerebral infarction & $\mathrm{N}$ \\
\hline 6 . & 67 & M & NA & - & NA & Cancer (mesopharynx), Pneumonia & $\mathrm{CD}$ \\
\hline 7 . & 60 & $\mathrm{~F}$ & $\mathrm{~N}$ & - & $\mathrm{N}$ & Plasmacytoma & $\mathrm{CD}$ \\
\hline 8 . & 81 & M & Eur & - & $\mathrm{N}$ & Diabetes mellitus, Gout & $\mathrm{N}$ \\
\hline 9 . & 70 & M & $\mathrm{N}$ & - & $\mathrm{N}$ & Cardiac disease & $\mathrm{N}$ \\
\hline 10. & 58 & M & NA & - & $\mathrm{N}$ & Cardiac disease & $\mathrm{N}$ \\
\hline
\end{tabular}

${ }^{*}$ Eur =Europe; $\mathrm{N}=$ none; $\mathrm{NA}=$ no answer; $\mathrm{SEA}=$ Southeast Asia.

$\dagger$ Main symptoms relating to giardiasis

$\ddagger$ Main history

$\S$ Administration of immunosuppressive drug or carcinostatic drugs $(\mathrm{CD})$

feature of the present study is that Giardia-positive cases were distributed in advanced age group $(>51$ years old). This tendency is not consistent with age distribution in developing countries (Gilman et al., 1985). The prevalence rate was comparable to those reported from Fukuoka, Tokyo and Shizuoka in Japan by Mako (1982), Kado et al. (1986) and Ichizawa et al. (1990) respectively. Occupation of the subjects with Giardia parasites was different.

A few subjects had symptoms related to Giardia infection (Table 2). Most of the subjects had history of malignant neoplasm and cardiac diseases, and some had been taking carcinostatic drugs. None of the subjects was infected with HTLV-I, although the disease is endemic in Kochi (Taguchi et al., 1983). One out of 8 subjects with Giardia parasites was resistant to the treatment with metronidazole. It has been reported that drug resistance in giardiasis is related with agammaglobulinemia, intestinal hyposecretion of $\operatorname{IgA}$, hypoacidity and etc. (Wolf 1975; Akahori et al., 1994). In the present metronidazole-resistant case, however, a serum immunoglobulin level was normal. It has been suggested that host's cellular cytotoxicity for the parasite is involved in chronic giardiasis (Smith et al., 1982). Monocyte counts in peripheral blood of several subjects positive for Giardia decreased after treatment with metronidazole (Fig 2). Monocyte-derived macrophages have been reported to have capacity to ingest Giardia trophozoites and to kill intracellular parasites (Hill and Pearson, 1987), although it remains to be solved that monocytes are important effector cell in vivo.

Fecal examination was done of all the member of a family living with one parasitologically-confirmed subject. None of the family members had been found

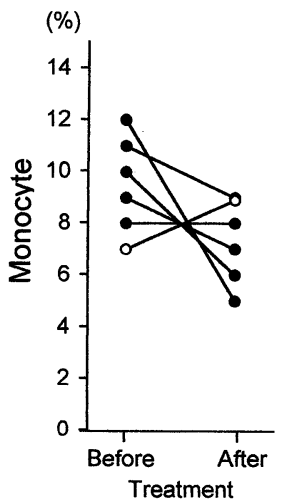

Figure 2 Monocyte rates in peripheral blood from subjects with Giardia organisms before and after treatment with metronidazole. Statistical analysis excluded data of which one patient (open circle) persisted in passing cysts of Giardia in his stool after treatment.

infected with Giardia. Most of the parasite-positive subjects had no pet animal. At least some isolates of Giardia have a wide range of host susceptibility. Therefore, it is possible that humans and a variety of animals naturally share the parasite (Baker and Gerschwin, 1987; Collins et al., 1987; Thompson 1992). Two subjects positive for the organism went abroad within last several years. Most of the positive cases in the present study were thought to be infected within their community, but the source of infection was not determined.

In conclusion, we showed the higher prevalence of Giardia spp. infection in advanced age group, when stool samples from subjects of 0 to 94 years of age were examined. Such a tendency might be caused by an immunological condition of the host subjects such as immunodepression by aging. Nowadays, in Japan, the 
ratio of advanced age group ha been increasing especially in Kochi Prefecture. Therefore, more attention should be given to such parasitic infections at laboratory stool examinations, in order to eliminate cyst carriers as potential source of the infection.

\section{ACKNOWLEDGMENTS}

Thanks are due to Dr. S.M. Shamszamann for his reading the manuscript.

\section{REFERENCES}

1) Akahori, H., Oomori, A., Nagatake, T., Matsumoto, K., Nagao, T. and Kanbara, K. (1994): A case of giardiasis. Clin. Parasitol., 5, 36-37 (in Japanese)

2 ) Baker, D.G., Strombeck, D.R. and Gerschwin, L.J. (1987): Laboratory diagnosis of Giardia duodenalis infection in dogs. J. Am. Vet. Med. Assoc., 190, 53-56

3 ) Collins, G.H., Pope, S.E., Griffin, D.L., Walker, J. and Connor, G. (1987): Diagnosis and prevalence of Giardia spp. in dogs and cats. Aust. Vet. J., 64, 89-90

4 ) Gilman, R.H., Brown, K.H., Visvesvara, G.S., Mondal, G., Greenberg, G., Sack, R.B., Brandt, F. and Khan, M.U. (1985): Epidemiology and serology of Giardia lamblia in a developing country: Banglandesh. Trans. Roy. Soc. Trop. Med. Hyg., 79, 469-473

5 ) Gleason, N. and Healy, G. (1965): Modification and evaluation of Kohn's one--step staining technic for intestinal protozoa in feces or tissue. Amer. J. Clin. Pathol., 43, 494

6) Henriksen, S.A. and Pohlenz, J.F.L. (1981): Staining of cryptosporidia by a modified Ziehl-Neelsen technique. Acta. Vet. Scand., 22, 594-596

7 ) Hill, D.R. and Pearson, R.D. (1987): Ingestion of Giardia lamblia trophozoites by human mononuclear phagocytes. Infect. Immun., 55, 3155-3161

8 ) Ichizawa, T., Kato, H., Mochizuka, I., Kurita, M., Senoh, K. and Suzuki, N. (1990): Giardiasis in Fujieda and its neighboring towns, Shizuoka Prefecture. Jpn. J. Trop. Med. Hyg., 18, 333-339 (in Japanese)
9 ) Kado, K., Naka, H., Kiyose, H., Sugiyama, E. and Shinonaga, S. (1986): Recent prevalent condition of intestinal parasites of the inhabitants in Tokyo and neighboring areas. J. Jpn. Assoc. Infect. Dis., 60, 13171323 (in Japanese)

10) Kulda, J. and Nohýnková, E. (1978): Flagellates of the human intestine and of intestines of other species. In: Parastic Protozoa, Vol. 2, pp. 1-138. Academic Press, New York

11) Mako, T. (1982): Survey of intestinal protozoan in Fukuoka City, Japan. Jpn. J. Med. Tec., 31, 660 (in Japanese)

12) Moorehead, P., Guasparini, R., Donovan, C.A., Mathias, R.G., Cottle, R. and Baytalan, G. (1990): Giardiasis outbreak from a chlorinated community water supply. Can. J. Public Health., 81, 358-362

13) Peterson, L.R., Carter, M.L. and Hadler, J.L. (1988): A food borne outbreak of Giardia lamblia. J. Infect. Dis., 157, 846-848

14) Pickering, L.K., Evans, D.G., DuPont, H.L., Vollet, J.J. and Evans, D.J. (1981): Diarrhea caused by Shigella, Rotavirus, and Giardia in day care centers: prospective study. J. Pediatr., 99, 51-56

15) Smith, P.D., Gillin, F.D., Spira, W.M. and Nash, T.E. (1982): Chronic giardiasis: Studies on drug sensitivity, toxin production, and host immune response. Gastroenterology., 83, 797-803

16) Taguchi, H., Fujishita, M., Miyoshi, I., Mizobuchi, I. and Nagasaki, A. (1983): HTLV antibody positivity and incidence of adult T-cell leukaemia in Kochi Prefecture, Japan. Lancet, 2 (8357), 1029

17) Takeuchi, T. and Miyahira, Y. (1989): Parasites and sexually transmitted diseases. The Saishin-Igaku., 44, 709-716 (in Japanese)

18) Thompson, R.C.A., Reynoldson, J.A. and Mendis, A.H. W. (1993): Giardia and giardiasis. In: Advances in PARASITOLOGY, Vol. 32, pp. 71-160 Academic Press, New York

19) Thompson, R.C.A. (1992): Parasitic zoonoses-Problems created by people, not animals. Int. J. Parasitol., 22, 555561

20) Wolf, M.S. (1975): Giardiasis. JAMA., 233, 1362-1365 